\title{
Quando uma imagem não diz tudo: análise do discurso da logomarca da Estratégia Saúde da Família à luz do conceito de família contemporânea
}

\author{
When an image does not reveal everything: analysis of the \\ discourse of the Family Health Strategy logo in the light of the \\ concept of the contemporary family
}

Gilberto Leão Fragoso (https://orcid.org/0000-0002-8859-5437) ${ }^{1}$

\footnotetext{
${ }^{1}$ Escola de Saúde Pública de Minas Gerais. Av. Augusto de Lima 2061, Barro Preto. 30190-009 Belo Horizonte MG Brasil.

leaofragoso@yahoo.com.br
}

\begin{abstract}
This article deals with exploratory research with the objective of analyzing the discourse of the Family Health Strategy (ESF) logo in the light of the concept of the contemporary family. The analysis was made using the "Semiolinguistic" theory of Patrick Charaudeau of the French School of Discourse. The result revealed a discursive framework with important restrictions regarding the act of language as the monologue aspect of the process and a subject of non-institutional speech constituted by the advertising agent hired by the Ministry of Health. In the analysis, a discrepancy was found between the verbal content that shows the expression "Family Health" tending to the comprehensiveness of the policy implemented by the ESF, when compared with the image aspect, the elements of which demonstrated the predominance of the traditional family. The relevance of multiple contexts, such as cultural, social and gender aspects, which influenced the interpretation of mixed texts, was studied. The need to reformulate the brand was pointed out to make it more comprehensive and consistent with the new contemporary family formats. Future studies are suggested that address the limiting character implicit in the concept behind the logo in a more critical and incisive manner.
\end{abstract}

Key words Family, Family Health Strategy, Language studies
Resumo O artigo trata de uma pesquisa exploratória com o objetivo de analisar o discurso da logomarca da Estratégia Saúde da Família (ESF) à luz do conceito de família contemporânea. A análise se deu pela teoria Semiolinguística de Patrick Charaudeau da Escola Francesa do Discurso. O resultado mostrou um quadro discursivo com importantes restrições quanto ao ato de linguagem como o aspecto monologal do processo e um sujeito de fala não institucional constituído pelo agente publicitário contratado pelo Ministério da Saúde. $\mathrm{Na}$ análise evidenciou-se uma discrepância entre o conteúdo verbal que mostra a expressão "Saúde da Família" tendendo à abrangência da política implementada pela ESF quando comparado à parte imagética cujos elementos demonstraram o predominio da família tradicional. Trabalhou-se a relevância de múltiplos contextos como o cultural, o social e o de gênero que influenciam na interpretação de textos mistos. Apontou-se a necessidade de reformulação da marca para torná-la mais abrangente e condizente com os novos formatos de família na contemporaneidade. Sugerese estudos futuros que explorem, de maneira mais crítica e incisiva, o caráter limitante implícito na visão da logomarca.

Palavras-chave Família, Estratégia Saúde da Família, Estudos de linguagem 


\section{Introdução}

O olhar historiográfico acerca da formação da família na sociedade brasileira mostra que o avanço da história social foi relevante para colocar em debate o tema relacionado a essa instituição. No entanto, esse cenário de discussão não foi suficiente para se estabelecer perspectivas de mudanças quanto à estrutura patriarcal que marcou a formação da família brasileira ${ }^{1}$.

Nesse sentido, ainda há predomínio da família nuclear composta hegemonicamente pela tríade pai-mãe-filho, o que dificulta o entendimento das novas configurações familiares que fundamentaram o despontar de novas relações no seio das famílias².

Nessa perspectiva, a evolução histórica da família contribui para o entendimento de novas relações de poder que culminaram - sobretudo em meados do século XX e no século XXI - no formato da família contemporânea, especialmente em que se vislumbram novos papéis em termos sociais e de relações de gênero, nesse caso determinando o protagonismo da mulher ${ }^{3}$.

Dada a importância da família para a implementação de ações de cuidado à saúde, o Sistema Único de Saúde (SUS), adotou políticas públicas que colocaram essa instituição no centro da discussão. Para isso, houve a necessidade de tratar a família como "o sujeito da atenção, o que exige uma interação da equipe de saúde com esta unidade social e o conhecimento integral de seus problemas de saúde e das formas singulares de abordagem familiar"4.

Por isso, concorda-secom $\operatorname{Trad}^{3}$ e Mari et al. ${ }^{5}$ quanto à necessidade de reflexão acerca da definição ou concepção de família que tem permeado a implementação das políticas sociais com o intuito de se colocar em prática os programas de atenção à saúde. Nota-se a necessidade de aprofundamento acerca de como essas concepções de família se potencializam e promovem interferências quanto às ações que são desenvolvidas no campo do trabalho.

Nesse meandro, o problema que fomentou a pesquisa foi a indagação quanto à abrangência da marca gráfica que tem sido utilizada oficialmente pelo Ministério da Saúde para representação da Estratégia Saúde da Família (ESF).

A justificativa para o desenvolvimento desse trabalho é a relevância social de estudos que envolvem a temática da família quando a abordagem tem correlação com o campo da saúde. Além disso, ressalta-se a importância da discussão desta marca que tem a pretensão de ser a identidade visual de uma política de cunho universal.
O objetivo do trabalho foi realizar uma análise do discurso da marca gráfica da ESF frente ao conceito de família na contemporaneidade a partir da teoria Semiolinguística de Charaudeau, levando-se em consideração aspectos relacionados a contextos diversos.

\section{Métodos}

O estudo deu-se através da realização de uma pesquisa exploratória já que esta possibilita melhor familiaridade com o problema proposto tornando-o potencialmente mais visível.

Para uma abordagem conceitual fez-se uma explanação teórica da família brasileira para situar essa instituição no tempo contemporâneo. Com isso, tem-se subsídios para a análise do discurso da imagem utilizada na marca gráfica da ESF, corpus da pesquisa.

Partiu-se da hipótese de que o instrumento gráfico analisado neste estudo não seja capaz de abranger a todos os formatos de família que se configuram na contemporaneidade.

$\mathrm{O}$ autor principal que serviu de embasamento para o estudo foi Charaudeau, da Escola Francesa de análise do discurso através da teoria semiolinguística. Preocupou-se, também, com múltiplos contextos que têm o potencial de influenciar em discursos transmitidos.

Os elementos discutidos na semiolinguística apontam que o desejo de se desvendar algo assim como o de confrontar opiniões diversas que advém de culturas diferentes acerca de determinada temática, são fatores motivadores para a adoção dessa teoria ${ }^{7}$.

Para a produção do ato de linguagem, Charaudeau $^{7}$ descreve o processo de interação que se estabelece entre um sujeito comunicante e outro interpretante e expõe que, para a análise de um texto, não é necessário se dar conta dos pontos de vistas dos envolvidos na codificação e decodificação da mensagem, mas sim de "possíveis interpretativos que surgem (ou se cristalizam) no ponto de encontro dos dois processos de produção e de interpretação".

Já Maingueneau ${ }^{8}$ tratou de descrever a importância da valorização do contexto em que o receptor está inserido para que se efetive esse processo de interpretação. Para ele, o ato de enunciação é assimétrico já que "a pessoa que interpreta o enunciado reconstrói seu sentido a partir de indicações presentes no enunciado produzido [...]".

Por fim, se apresenta o quadro enunciativo (Figura 1) que trata da representação do disposi- 


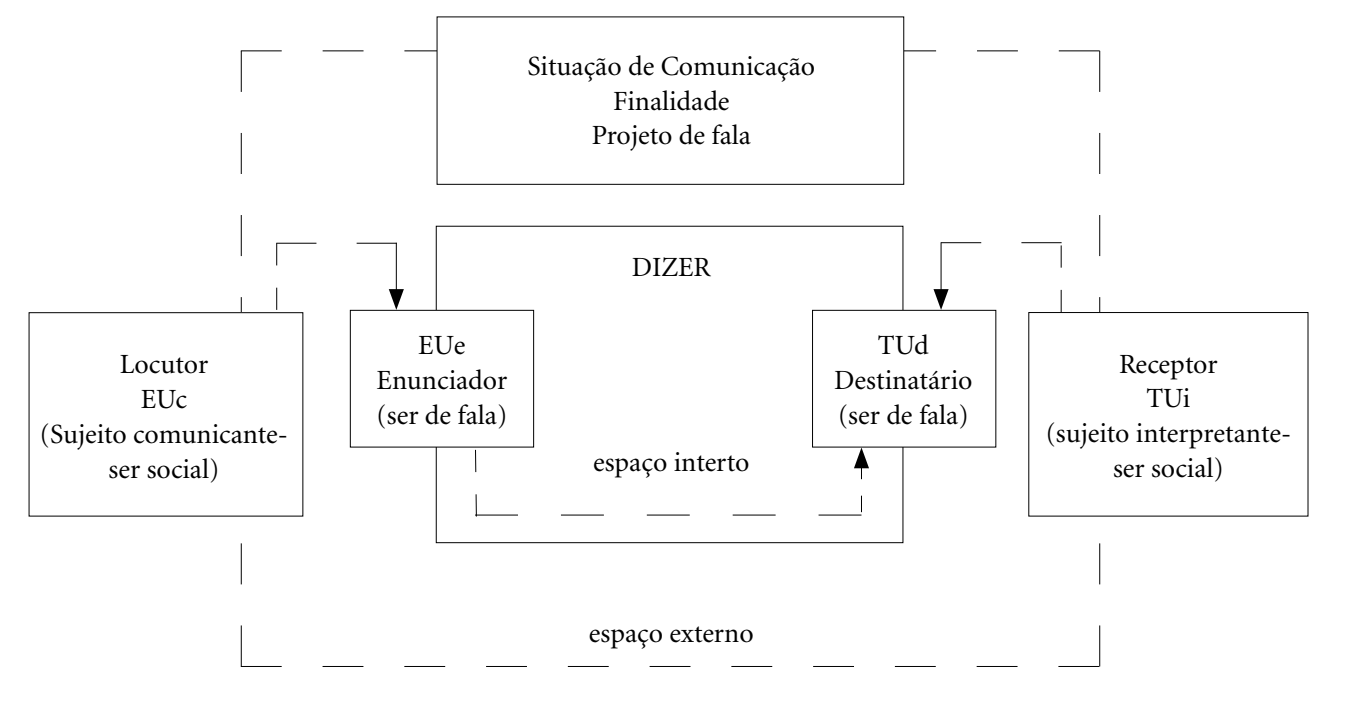

Figura 1. Situação de comunicação.

Fonte: Charaudeau ${ }^{7}$.

tivo de encenação da linguagem com a finalidade de fornecer um norte para a aplicação da Teoria Semiolinguística ${ }^{7}$.

\section{Resultados e discussão}

O conceito de família tem sofrido alterações, desde termos estruturais, perpassando pelos papéis exercidos pelos elementos constituintes do seio familiar até as novas relações de gênero e entre gerações na contemporaneidade. $\mathrm{O}$ desfecho foi a modificação desses papéis no sentido de torná -los menos hierarquizados e mais flexíveis ${ }^{3}$.

No que tange às modificações em termos de estrutura, esse autor ${ }^{3}$ ressalta que indicadores sociodemográficos mostram a multiplicação de arranjos que destoam do padrão típico da família brasileira, o que faz despontar novas formas de se estabelecer composições familiares a partir de núcleos monoparentais, especialmente aqueles chefiados por mulheres que experimentam um novo cenário de inclusão e pela observância da diminuição no tamanho das famílias ocasionado pelo decréscimo progressivo do número de filhos.

Porém, não se nota uma homogeneidade no que tange a essa evolução, sugerindo que esse fato é marcado por determinantes culturais diversificados e processos de urbanização diferentes devido à dimensão geográfica do Brasil ${ }^{3}$.
Mas, as consequências dessas mudanças permeiam as transformações das relações tanto de parentesco quanto de representações no interior das famílias, o que contribui para a modificação de papéis tradicionalmente estabelecidos, constituindo o que se denomina de nova família²

Nesse contexto, inúmeros formatos existem e coexistem transformando a maneira de ver o núcleo familiar contemporâneo. Importante destacar que "a família continua sendo espaço para a formação e construção de identidades e de protagonismo no mundo em transformação" ${ }^{2}$.

No caso em que se vislumbra, na evolução da própria sociedade, a ampliação do que seriam as famílias com suas múltiplas formas, torna-se relevante uma reflexão no sentido de desvendar os elementos que constituíram a marca da ESF cujo foco prioritário de políticas de saúde colocou a família brasileira, em todas as suas nuances, como o centro da atenção.

Assim, apresenta-se a imagem, Figura 2, que serviu de corpus à pesquisa.

Da análise de informações contidas no Manual de Uso de Marcas do Ministério da Saúde entendeu-se que a logomarca tenha cunho publicitário já que a referida marca tem como "objetivo principal levar as práticas e ações de saúde para mais perto das famílias [...]"9.

A análise desse corpus deu-se pela identificação dos dados externos e internos do contrato 


\section{$B$}

Figura 2. Marca oficial da Estratégia Saúde da Família.

Fonte: Ministério da Saúde ${ }^{9}$.

de comunicação da publicidade de marca para a evidenciação das restrições situacionais e discursivas uma vez que, conforme Charaudeau ${ }^{6}$, tratar de estratégias somente fará sentido diante de um quadro de coerções a partir dos quais o sujeito faz escolhas para buscar a efetivação de seu objetivo comunicativo.

Depois, focalizou-se a instância do texto em sua composição verbal e visual para possibilitar a investigação das estratégias discursivas acionadas pela instância de produção nos espaços de legitimação, credibilização e captação que são oferecidos pelas margens de manobra do contrato de comunicação em questão. E, em seguida, fez-se uma análise contextual para o levantamento de um possivel interpretativo.

No escopo em que se configura o corpus deste estudo tem-se como instância comunicante - o EUc - o Governo Federal, responsável pelas diretrizes de saúde. A publicidade é de responsabilidade do Ministério da Saúde que, por sua vez, pode contratar serviço terceirizado. A logomarca em estudo foi confeccionada pela agência Borghierch Lowe. Já a instância interpretante (TUi) é constituída por todo o público que entra em contato com os materiais publicitários produzidos.

No que se refere à instância enunciadora (EUe) ela é representada pelo Ministério da Saúde/SUS que é o responsável pela assinatura dos materiais publicitários institucionais desta pasta. A instância destinatária (TUd) é constituída pelo público para o qual os benefícios da estratégia de cuidado à saúde são direcionados.

Então, pode-se representar o quadro do ato de linguagem de publicidade dessa identidade vi- sual da Estratégia Saúde da Família do Ministério da Saúde conforme a Figura 3.

A imagem está presente "na variedade de produtos culturais expressivos de determinada sociedade". E, portanto, pode ser percebida de formas diferentes por quem a produziu e por quem a está olhando ${ }^{10}$.

No entanto, a despeito de determinados sujeitos estarem inseridos no mesmo momento histórico e participando do mesmo grupo cultural, poderá haver interpretações diferentes possibilitando a recriação de sentidos e significados ${ }^{10}$.

Portanto, olhar a imagem pelo intermédio da análise do discurso significa "entender o nãoverbal em sua discursividade" fazendo "projetar outro foco sobre a imagem e desvelar outras nuances em torno de um objeto [...]". Para tanto, salientam que "a imagem se define como um dispositivo que pertence a uma estratégia de comunicação" sendo também um operador de simbolização ${ }^{11}$.

Quanto ao processo de interpretação que vai ao encontro da análise do discurso pressupõe-se a relação estabelecida entre objetos icônicos "com a cultura, o social, o histórico, com a formação social dos sujeitos [...]". Daí que, "ao se interpretar a imagem pelo olhar, [...], apreende-se a sua matéria significante em diferentes contextos" ${ }^{\prime 1}$.

Nessa perspectiva de atribuição de sentido, em que se torna relevante analisar o jogo de disposição de objetos imagéticos, é importante que se busque referenciar a forma como as cores são significadas para o ser humano.

Nesse sentido, Guimarães ${ }^{12}$, postula que, para além da percepção individual para a física da cor, "é possível obter-se uma significação precisa para determinada cor em determinado texto cultural". Para que seja possível essa invariante e estabelecer uma leitura homogênea esse autor diz que "a aplicação da informação cromática deverá estar combinada com outros elementos sígnicos além da própria cor" sendo que um desses elementos pode ser a aplicação, ao mesmo tempo, da cor simbolicamente oposta.

Os processos físicos de decomposição da luz atribuído a aspectos fisiológicos que envolvem a captação do raio luminoso pelo olho humano e o repertório cultural decorrente da interação do homem com o mundo traz a possibilidade de atribuição de carga emocional à cor. Cita o vermelho que, analisado à luz desses aspectos, traz consigo a simbologia da agressividade, formando uma imagem mais forte enquanto o azul, cor de oposição física ao vermelho, é a cor que transmite tranquilidade $^{12}$. 
Figura 3. Ato de linguagem da publicidade da marca ESF do Ministério da Saúde.

Fonte: adaptado de Charaudeau ${ }^{7}$.

Resgata-se, assim, a questão da geração de efeitos de sentidos opostos, o que ocorre com os gêneros masculino versus feminino, em decorrência da oposição proporcionada pelo uso de determinadas cores, como tratado por Guimarães ${ }^{12}$. Essa polaridade é estabelecida no contexto sociocultural que permite a leitura de um jogo de imagens que coloca o homem e a mulher em polos opostos, simplesmente a partir de atribuição de cores diferentes.

Partindo para o contrato de comunicação, nos dizeres de Charadeau ${ }^{7}$, ele ocorre no espaço situacional em que a instância comunicante defronta-se com determinadas restrições das quais dependem $o$ ato de linguagem.

Uma dessas restrições refere-se ao desconhecimento da identidade da instância de recepção já que qualquer indivíduo deve ser considerado um possível agente interpretante da logomarca em questão.

Além disso, a marca da ESF está presente em uniformes de forma padronizada e, devido a amplitude de sua abrangência, a logomarca alcança todo o território brasileiro. Também, os programas de cuidado à saúde do Brasil têm visibilidade internacional, o que possibilita a globalização da logomarca.

Assim, a identidade social desta instância de recepção configura-se heterogênea posto que existem sujeitos inseridos em contextos culturais distintos, cujos saberes de mundo também são diversificados. Com isso, defronta-se com a dificuldade de se estabelecer a identidade da instância destinatária com relação à sua idade, sexo, status social e econômico e quanto aos seus estados afetivos e motivações. A instância comunicante, então, procura vincular a identidade da instância destinatária à identidade do público-alvo para o qual o Sistema Único de Saúde direciona suas ações conforme a Política Nacional de Atenção Básica ${ }^{13}$.

Com relação ao dispositivo adotado para veiculação da marca, este tem seu uso estabelecido em todos os espaços de divulgação do serviço da ESF. Porém, há uma importante restrição do contrato de comunicação publicitário que é a situação monologal.

Como os parceiros do ato de linguagem não estão presentes fisicamente para que se tenha a troca comunicativa isso pressupõe que a instância comunicante não irá perceber as reações da instância interpretante. Nesse caso, será possível apenas se estabelecer esta reação no plano imaginário. A produção do enunciado ocorrerá a partir destas suposições, sem a possibilidade de retificação ou complementação do enunciado no momento da troca.

Com relação às características da marca da ESF, deve-se introduzir a condição da finalidade do ato de linguagem. E, conforme $\mathrm{MS}^{9}$, a logomarca "tem como objetivo principal levar as práticas e ações de saúde para mais perto das 
famílias [...]”, o que implica na necessidade da instância comunicante implementar meios para fazer com que a instância interpretante se sinta contemplada nessa proposição. Isso quer dizer que o interlocutor precisa pensar ser verdadeiro o que está sendo dito na representação gráfica da ESF. O contrato de comunicação da publicidade em estudo, portanto, tem como uma de suas restrições a necessidade do ato de linguagem atender a essas necessidades do fazer.

No que tange às restrições do propósito comunicativo essas advêm das diretrizes dadas pela Política Pública do SUS para a atenção básica. Assim, a instância comunicante necessariamente deverá estabelecer qual a família que se configurará na cena discursiva para se estabelecer os mecanismos que visem à transmissão do discurso adequado ao texto veiculado na identidade visual da marca.

O que garante o espaço de locução da instância enunciadora é o dispositivo utilizado para veiculação, nesse caso sendo determinado pelo ambiente virtual e pelas estampas nos uniformes.

No entanto, para que a instância destinatária tenha interesse em repercutir tal marca, o enunciador deve implementar meios para a construção de uma relação persuasiva frente ao público-alvo. Para tanto, buscará formas para se legitimar como autoridade, dar credibilidade ao que está sendo dito e captar a instância destinatária por meio de estratégias discursivas.

Para introduzir a tematização da troca comunicativa, a instância enunciadora deverá escolher um modo de organização do discurso que seja mais adequado ao propósito estabelecido em seu ato de linguagem. Como o modo de organização descritivo permite que a instância enunciadora acione estratégias discursivas para identificar, situar e qualificar algo - procedimentos necessários para a construção de imagens na representação de família como pretende a ESF -, tem-se que o descritivo é o modo predominante neste texto publicitário.

Quanto à legitimidade, a fala do sujeito enunciador pode advir tanto de sua autoridade em decorrência de sua constituição enquanto ser institucional como de sua posição de autoridade que se constrói no discurso e ainda pode ser advinda da própria situação de comunicação ${ }^{5,8}$.

$\mathrm{Na}$ situação monologal há dificuldade de questionamento da fala do enunciador devido à pouca interação entre os sujeitos e, no caso desta pesquisa, o sujeito comunicante traz para a cena do ato de linguagem um sujeito enunciador que se constitui de uma instância ligada ao Gover- no Federal do Brasil, o que confere um status de poderio simbólico institucionalizado trazendo maior legitimidade à fala.

O processo de credibilização será evocado com a finalidade de tornar o discurso mais confiável. No caso em tela nota-se um posicionamento de neutralidade, mas que possibilita o processo de engajamento por parte da instância enunciadora. Isso se percebe pela expressão "Saúde da Família" que, em decorrência de sua construção, funciona como um elemento de persuasão e sedução quanto à pretensão da ESF. Nota-se que a utilização das palavras - posicionamento e escrita em caixa alta e negrito - pode denotar um significado abrangente do que a ESF oferece, desviando o foco da imagem que está vinculada à logomarca.

Já a captação, nos dizeres de Charaudeau ${ }^{7}$, é utilizada pelo enunciador com a finalidade de acionar estratégias discursivas que proporcionarão um compartilhamento e aceitação de ideias pela instância destinatária. No caso da marca em estudo, a utilização dos termos "saúde" e "família”, a partir de sua associação com a Política de Saúde do SUS, possibilita maior familiaridade do interlocutor facilitando o processo de apreensão do discurso pretendido pelo enunciador.

Uma vez que o contexto em que os sujeitos estão inseridos potencialmente é capaz de interferir no processo de significação conforme se extrai de Charaudeau ${ }^{7}$, Maingueneau ${ }^{8}$ e Araújo e Cardoso $^{14}$ e tendo-se em vista que a logomarca representa o programa de atenção à saúde, num percurso temporal desde o Programa de Saúde da Família implementado pelo SUS em 1994, aprimorado pela Estratégia Saúde da Família, o contexto da época para esta instituição já era o de novas configurações nos seios familiares como discutido por $\operatorname{Trad}^{3}$, Oliveira ${ }^{2}$ e problematizado por Goldani ${ }^{15}$.

Mas, por outro lado, um ethos construido acerca da família fez perpetuar um discurso que evidencia a representação de família tradicional como a hegemonicamente aceita. Este fato é reforçado pelo poderio simbólico adquirido pelos sujeitos de fala cuja análise da logomarca remete ao indivíduo urbano comprovado pela existência de um espaço com formas urbanas no plano de fundo, o que traz à cena o ambiente típico de convivência do indivíduo da cidade que, historicamente, tem acumulado capital simbólico e cultural fazendo predominar o ethos construído acerca de família, como refletido acima.

Isso reforça o possivel interpretativo de que o conceito de família que emana dessa identidade 
visual é o da família tradicional e, nessa direção, o discurso extraído da imagem vinculada analisada também aponta para a família nuclear sem se considerar os novos arranjos familiares da contemporaneidade.

Além disso, verificando-se os elementos que têm o intuito de representar as formas humanas notam-se dois maiores de mesma forma e tamanho nas cores azul claro e vermelho e o outro menor - à frente - na cor branca. Na associação desses elementos à escrita logo abaixo, "Saúde da Família", a alusão possível é de que representam um núcleo familiar.

A utilização das cores opostas que traduz a dicotomia azul versus vermelho, pode ser percebida na logomarca numa alusão aos aspectos culturais do contexto de gênero que atribuem o azul como a cor masculina. É importante ressaltar que o vermelho tende ao rosa quando sua tonalidade se torna mais clara - cor predominantemente feminina nesta representação de gênero ${ }^{12}$.

Quanto ao elemento menor que está na cor branca, discutida por Guimarães ${ }^{12}$, como uma simbolização de pureza e neutralidade, um significado possível é de que representa a criança. Percebe-se que este elemento, em quase sua totalidade, coincide com a maior em vermelho (o feminino) e se posiciona mais distante do elemento azul (o masculino), o que demonstraria o cuidado doméstico com o filho evidenciado por Bruschini $^{16}$ - tarefa atribuída culturalmente à mãe.

Vê-se, na imagem, que o elemento azul estando posicionado logo atrás dos demais transmite um significado do "protetor", o que evidencia traços do patriarcado ${ }^{17}$.

Isso posto, ainda que os sujeitos interpretantes, como discutido por Charaudeau ${ }^{7}$, sejam diversos e os discursos potencialmente sofram variações dependendo do contexto sociocultural que permeia o interlocutor, a persistência de um ethos que reforça a família nuclear como representação universal acaba por determinar um discurso de família tradicional quando se analisam os elementos presentes na imagem da marca ESF.

\section{Considerações finais}

As novas configurações da família brasileira que se figuram na contemporaneidade e sua relação com a política pública de cuidado à saúde instituída no Brasil foi o cenário propulsor que motivou o interesse no estudo em questão. Apontouse uma inquietação relacionada à abrangência da logomarca utilizada para a representação da
Estratégia Saúde da Família - programa de maior relevância no âmbito da atenção primária e que tem o foco no núcleo familiar - frente aos novos formatos de família. Extraiu-se do Manual de uso de Marcas do Ministério da Saúde evidências de que esta marca tenha cunho publicitário.

A pergunta que fomentou tal inquietação está relacionada à representação da marca utilizada por este programa quanto à abrangência de todos os formatos de família do tempo contemporâneo.

Para buscar um caminho que respondesse à indagação, fez-se uma análise do discurso na perspectiva de Patrick Charaudeau. Dadas as peculiaridades do corpus de pesquisa, focou-se em referências que trabalharam o estudo de elementos que mesclaram textos mistos com partes icônicas e verbais.

Com isso, vislumbrou-se a confirmação ou a refutação da hipótese de que tal logomarca não seria capaz de abranger a todas as configurações da nova família que está constituída, não apenas pela estrutura nuclear composta por pai-mãe-filho no modelo tradicional, mas por outros formatos como constituições monoparentais, casais homossexuais, casais sem filhos, mulheres que são arrimo de família, dentre outros.

Tendo-se como base a teoria Semiolinguística do Discurso de Patrick Charaudeau, viu-se que o contrato de comunicação estabelecido entre os interlocutores determinou certas restrições situacionais e discursivas ao ato de linguagem que impossibilita uma homogeneidade quanto ao discurso emitido pela marca da ESF. Isso ocorre porque, de acordo com as proposições levantadas nesta pesquisa, os agentes receptores são heterogêneos e estão inseridos em contextos diversos não sendo possível estabelecer como a logomarca é interpretada por cada indivíduo dada a dimensão de abrangência do programa e a visibilidade internacional desta política de governo.

Constatou-se que o sujeito de fala, no caso o Ministério da Saúde, é um ser institucional e responsável por determinar diretrizes de cuidado à saúde, o que contribui para a credibilidade do que se pretende transmitir. Porém, por outro lado, inibe o potencial de críticas, especialmente porque uma importante restrição do ato de linguagem diz respeito à situação monologal da ação de comunicação evidenciado no processo de criação dessa logomarca. Esse fato dificulta a interação dos interlocutores no sentido de possibilitar uma versão mais dialogal.

No entanto, reforçou-se que a análise deve levar em consideração a existência de outro su- 
jeito que se constituiu do agente publicitário - a agência Borghierh Lowe - contratada à época pelo Ministério da Saúde. Portanto, os elementos utilizados na confecção da marca também advêm do prisma desse outro ser de fala e não se pode garantir que o conceito de família para esta empresa coincida com o preconizado pelo órgão de Governo representado pelo Ministério da Saúde.

Viu-se também que o uso de palavras em negrito na expressão "Saúde da Família" estabeleceu um discurso tanto de credibilidade quanto de captação acerca da pretensão da Estratégia Saúde da Família. Isso possibilitou um possível interpretativo de que tal programa é abrangente e, portanto, alcançaria a todas as famílias com suas novas configurações. No entanto, em contraposição ao texto verbal que tende à abrangência, a análise das características da parte imagética evidenciou o predomínio da família tradicional, que nos remeteu à restrição.

No que se refere ao contexto temporal de construção da logomarca, discutiu-se que, naquele momento, os novos formatos de família já estavam se estabelecendo no Brasil. Caso esse fato tivesse sido levado em consideração haveria a probabilidade de uma imagem mais abrangente. Perdeu-se a oportunidade de tornar a marca mais condizente com as inúmeras configurações de núcleos familiares que se desenhavam.

Evidenciou-se a importância de se levar em consideração o uso das cores já que sua significação não se desprende de contextos culturais e de gênero. Portanto, encontrou-se a dicotomia masculino versus feminino sob duas vertentes: uma quando se utilizou cores antagônicas remetendo à dualidade de oposição e outra quando se usou cores que culturalmente remetem a gêneros diferentes.

O conteúdo imagético confrontou elementos que simbolizavam seres humanos e utilizaram as cores azul claro e vermelho para caracterizar uma representação de família. Daí, chegou-se à conclusão da existência de um sentido de gêneros opostos, no caso homem versus mulher, o que denotou a significação da família tradicional na representação icônica da marca.

Extrapolou-se para contextos sociais de gênero que decorreram da evidenciação do posicionamento dos elementos na imagem utilizada pela logomarca reforçando a divisão sexual do trabalho ainda presente na sociedade brasileira, reforçando o papel de cuidadora atribuída às mulheres e de proteção, inclusive no aspecto financeiro, relegado ao homem.

Salientou-se e se confirmou a necessidade de revisão da marca para que a mesma abranja aos formatos de família da atualidade utilizando uma imagem que envolva aos casais monoparentais, mulheres ou homens que vivem sozinhos, indivíduos portadores de deficiência, casais sem filhos e outros. Isso possibilitaria um sentimento de pertencimento quanto ao que se absorve da logomarca, o que também possibilitaria maior adesão ao serviço oferecido pela rede de atenção à saúde.

Apesar de que a hipótese levantada neste estudo tenha sido confirmada, salientou-se que esta pesquisa somente envolveu a possibilidade de um sentimento de não pertencimento por parte de famílias que não se encaixam no formato tradicional extraído da logomarca, corpus deste estudo.

Sugere-se, para estudos futuros, uma abordagem mais crítica e incisiva do caráter limitante implícito na visão da logomarca da ESF, podendo-se evidenciar o estereótipo e o preconceito sociocultural e de gênero presente na construção da mesma. Além disso, outras pesquisas poderão ser realizadas para apontar os interesses mercadológicos que influenciaram a construção da marca gráfica pela agência contratada pelo Ministério da Saúde. 


\section{Referências}

1. Samara EM. A família brasileira. São Paulo: Editora Brasiliense; 2006. (Série Tudo é história, 71).

2. Oliveira NHD. Recomeçar: família, filhos e desafios [online]. São Paulo: Editora UNESP, Cultura Acadêmica, 2009. [acessado 2017 Ago 20]. Disponível em: http://books.scielo.org

3. Trad LAB. Família Contemporânea e saúde: significados, práticas e politicas públicas. Rio de Janeiro: Fiocruz, 2010.

4. Mendes EV. A construção social da atenção primária à saúde. Brasília: Conselho Nacional de Secretários de Saúde (CONASS); 2015.

5. Mari H, Machado LI, Mello R, organizadores. Análise do discurso: fundamentos e práticas. Belo Horizonte: Núcleo de Análise do Discurso, FALE/UFMG; 2001.

6. Gil AC. Como elaborar projetos de pesquisa. $4^{\mathrm{a}} \mathrm{ed}$. São Paulo: Atlas; 2002.

7. Charaudeau P. Linguagem e discurso: modos de organização. São Paulo: Contexto; 2008.

8. Maingueneau D. Análise de textos de comunicação. $4^{\mathrm{a}}$ ed. São Paulo: Cortez; 2005.

9. Brasil. Ministério da Saúde (MS). Manual de uso da marca Saúde da Família. [on line]. Brasília; 2012. [acessado 2017 Ago 20]. Disponível em: http://portalarquivos2.saude.gov.br/images/pdf/2013/outubro/18/doc4-181013.pdf

10. Vicente TAS. Metodologia de análise de imagens. Contracampo 2002.
11. Silva TD, Souza TC, Agustini C, organizadores. Imagens na comunicação e discurso. São Paulo, Belo Horizonte: Annablume, Fapemig; 2012.

12. Guimarães L. A cor como informação: a construção biofísica, linguística e cultural da simbologia das cores. São Paulo: Annablume; 2000.

13. Brasil. Ministério da Saúde (MS). Política Nacional de Atenção Básica. Brasília: MS; 2012.

14. Araujo IS, Cardoso JM. Comunicação e Saúde. Rio de Janeiro: Editora Fiocruz; 2007.

15. Goldani AM. As famílias brasileiras: mudanças e perspectivas. Cad. Pesq. 1994; (91):7-22.

16. Bruschini C. Uma abordagem sociológica de família. Rev. Bras. Est. Pop. 1989; 6(1):1-23.

17. Itaboraí NR. A família colonial e a construção do Brasil: Vida doméstica e identidade nacional em Gilberto Freyre, Sérgio Buarque de Holanda e Nestor Duarte. Revista Anthropológicas 2005; 9-16(1):171-196.

Artigo apresentado em 30/09/2018

Aprovado em 23/03/2019

Versão final apresentada em 25/03/2019 
